\title{
A Review on Halide Perovskites as Color Conversion Layers in White Light Emitting Diode Applications
}

\author{
Tugrul Guner and Mustafa M. Demir*
}

In the last decade, halide perovskites have attracted great interest due to many reasons, including their low cost, solution-processability, superior PL properties, broad range of color tunability, color purity, and defect tolerance, among others. They are in increasing demand for a wide range of applications, such as solar cells, light emitting diodes (LEDs), white LEDs (WLED), and lasers. Yellow phosphors have been heavily employed in solidstate lighting, since its illumination by blue yields white light with various optical features, such as high/low CRI, CCT, and luminous efficiency. However, phosphors as pigments are seldom found and are costly material. In this sense, halide perovskites may offer a promising alternative to phosphors for future solid-state lighting. In this study, the synthesis and optical properties of halide perovskites, as well as their application in WLED as a conversion layer are investigated.

\section{Introduction}

Solid-state lighting (SSL) is new generation of lighting that uses solid-state materials as light sources. ${ }^{[1-3]}$ This field has shown great progress in the last several decades, and has led to the development of light emitting diodes (LEDs), organic light emitting diodes (OLEDs), polymer light emitting diodes (PLEDs), and lasers. ${ }^{[4,5]}$ One type of SSL, white LEDs (WLEDs), has been commonly employed in streets, malls, homes, displays, and other places by replacing traditional lighting sources, e.g. incandescent and fluorescence lamps. ${ }^{[6-8]}$ Since LED is more efficient than traditional lighting sources in terms of energy consumption, this increasing replacement by, and use of, LEDs in general lighting is expected to lead to tremendous energy saving, ${ }^{[9]}$ expected to reach $75 \%$ by 2035 , according to the 2016 Solid State Lighting Forecast Report of U.S. Department of Energy. ${ }^{[10]}$

There are two main approaches to generating white light through LEDs. In the first approach, LEDs with different wavelengths including red, green, and blue (RGB) can be combined into multichip configuration. ${ }^{[11,12]}$ However, this

T. Guner, Prof. M. M. Demir

Department of Material Science and Engineering

Izmir Institute of Technology

35430 Izmir, Turkey

E-mail:mdemir@iyte.edu.tr

The ORCID identification number(s) for the author(s) of this article can be found under https://doi.org/10.1002/pssa.201800120.

DOI: 10.1002/pssa.201800120 approach involves a complex process: in order to get uniform white light distribution, driving currents of LED chips emitting different wavelengths must be matched, and their individual responses to aging and temperature should be balanced in every multichip device. In the second approach, a single UV or blue LED device can be combined in a LED package with a color conversion layer consisting of inorganic phosphor (pigment) particles such as oxide and nitride derivatives ${ }^{[13-20]}$ and also their association with a transparent polymer resin. ${ }^{[13-15,21-26]}$ This strategy is known as phosphor-converted WLED (pc-WLED).

A well-known and mainstream design of pc-WLED configuration involves a blue LED chip coated with yellow phosphor; one that is frequently used is cerium-doped yttrium aluminum garnet (YAG: $\mathrm{Ce}^{3+}$ ). In this setup, some portion of the blue light from LED excites the yellow phosphor, and white light is generated when the remaining portion of the blue light combines with the emitted yellow light. However, this approach suffers from low color rendering index (CRI) due to red deficiency and high correlated color temperature (CCT). To overcome this problem, additional phosphors (red phosphor, for instance) can be integrated into the system, ${ }^{[27,28]}$ or red, blue, and green phosphors (RGB) can be used as conversion layers over UV or near UV (n-UV) LED chips. With the growing use of pcWLEDs, phosphor consumption increases, and the need for phosphor will lead to challenges in the future in terms of their cost and availability, since they contain rare earth elements. ${ }^{[29]}$ In this sense, either phosphor consumption must be reduced ${ }^{[29-31]}$ or different luminescent materials need to be employed in a white LED package as an alternative to phosphors. Moreover, promising substitute candidates should achieve high CRI and luminous efficiency, as well as adjustable CCT to be used in WLEDs.

Halide perovskites have a unique crystal structure in the form of $\mathrm{ABX}_{3}$ (A: organic or inorganic cation, $\mathrm{B}$ : divalent metal cation, and $\mathrm{X}$ : halide anion $\left.\left(\mathrm{Br}^{-}, \mathrm{I}^{-}, \mathrm{Cl}^{-}\right)\right)$. To date, three possible cations for $\mathrm{A}$ have been reported that are able to stabilize the perovskite structure: $\mathrm{MA}^{+}, \mathrm{FA}^{+}$, and $\mathrm{Cs}^{+}{ }^{\left.+{ }^{32}\right]}$ Goldschmidt's Tolerance Factor, ${ }^{[33]} t=\left(r_{\mathrm{A}}+r_{\mathrm{X}}\right) / \sqrt{2\left(r_{\mathrm{B}}+r_{\mathrm{X}}\right)}$, where $r_{\mathrm{A}}, r_{\mathrm{B}}$, and $r_{\mathrm{X}}$ are respective ions in the $\mathrm{ABX}_{3}$ formula, hint to the formation of well-defined perovskite structure ${ }^{[34]}$ For instance, the majority of the 3-D perovskites were found to be (empirically) satisfying at $0.8 \leq t \leq 1.0$. Depending on the type of cation, halide perovskites can be divided into two groups. If the cation A of the perovskite 
involves either $\mathrm{MA}^{+}$or $\mathrm{FA}^{+}$or both, the structure belongs to the group of organometallic halide. On the other hand, if $\mathrm{Cs}^{+}$is employed, the structure is considered to be the all-inorganic halide perovskites. All-inorganic lead halide perovskites $(\mathrm{CsPbX})$ have been a known substance since $1890 \mathrm{~s}^{[35]}$; however, it took six decades to report the semi-conductive nature of these materials. ${ }^{[36]}$ Organometallic halide perovskites $\left(\mathrm{MAPbX}_{3}\right.$ or $\mathrm{FAPbX}_{3}$ ), by contrast, were introduced in the late $1970 \mathrm{~s}$ and have been known for almost 40 years. $^{[37]}$

The first known applications of these halide perovskites were performed using organic cations. These materials were found to show significant optical features-including small exciton binding energies, high charge carrier mobilities, and strong light absorption ${ }^{[38-40]}$-and led to the discovery of the highly efficient photovoltaic (PV) devices of halide perovskites. ${ }^{[41,42]}$ Since then, these materials, involving either organic or inorganic cations, have begun to gain significant attention, and these developments have recently brought halide perovskites into the research spotlight. ${ }^{[43-45]}$ Apart from their use in PV devices, they show more than $90 \%$ quantum yield in photoluminescence ${ }^{[46,47]}$; moreover, they possess unique properties, such as solutionprocessability, long carrier lifetimes, ease of fabrication, and wavelength tunability. ${ }^{[32,48-50]}$ These features make halide perovskites a strong candidate to be used in optical applications, including display technologies, WLEDs, and others. ${ }^{[39,51-56]}$ Particularly in the case of WLED applications, these halide perovskites may i) be used together with YAG phosphor; ii) replace YAG phosphor in YAG-based WLEDs; or iii) be used to obtain three main red-green-blue (RGB) colors separately over UV LED, as alternative to UV phosphors.

To get further insight into what degree of white LED studies involve phosphor or perovskites, statistical data of total publications and citations released in the last two decades were collected from Web of Science. These data are based on publications and citations related to the keywords white LED, white LED + phosphor, and white LED + perovskite; the statistical results are presented in Figure 1. It is obvious that white LED publications and citations have grown together with phosphor publications and citations and have closely followed each other since the beginning of the 2000s. However, publications and citations involving white LED and phosphors have begun to stabilize in recent years. This loss of interest in white LED studies may be the result of saturating phosphor studies, most probably due to reaching sufficiency in terms of materials

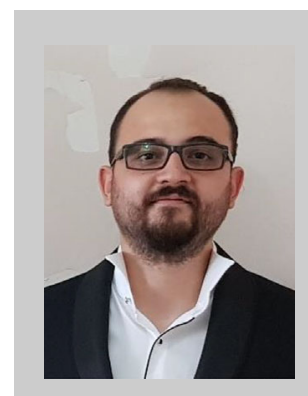

Tuğrul Güner received his B.S. from Physics Department of Ihsan Dogramaci Bilkent University, Turkey in 2011. He did his M.S. studies in Physics at Izmir Institute of Technology in 2015, and started Ph.D. programme in materials science and engineering at Izmir Institute of Technology, which he is currently studying under the supervision of Mustafa M. Demir. His current research interest is nanophotonics, optical materials, polymer optical (nano)composites, coating, machine learning, and quantum mechanics.

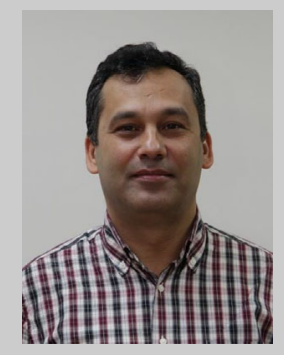

Mustafa M. Demir received his B.S. from Chemistry Department of Boğaziçi University, Turkey in 1999. He did his M.S. and Ph.D. studies in materials sciences and engineering programme at Sabancı University in 2001 and 2004, respectively. Later he moved to Max Planck Society Polymer Research Institute in Mainz, Germany as postdoc researcher under the supervision of Prof. Gerhard Wegner. Since 2007, he has a faculty position at Izmir Institute of Technology. His current research interest is polymer-based nanomaterials. He is now chairman of Department of Materials Science and Engineering of the institute.

discovery and their optimization. On the other hand, perovskiterelated white LED publications and citations only began in 2012, and have grown rapidly since then. It will be no surprise if this new technology will surpass the phosphor-related studies in a short time, and then lead to rapid growth for white LED publications and citations.

This topical review will summarize recent trends in halide perovskites that were used in WLED applications. The following topics will be briefly discussed: first, recent developments in the preparation of halide perovskites; second, their optical
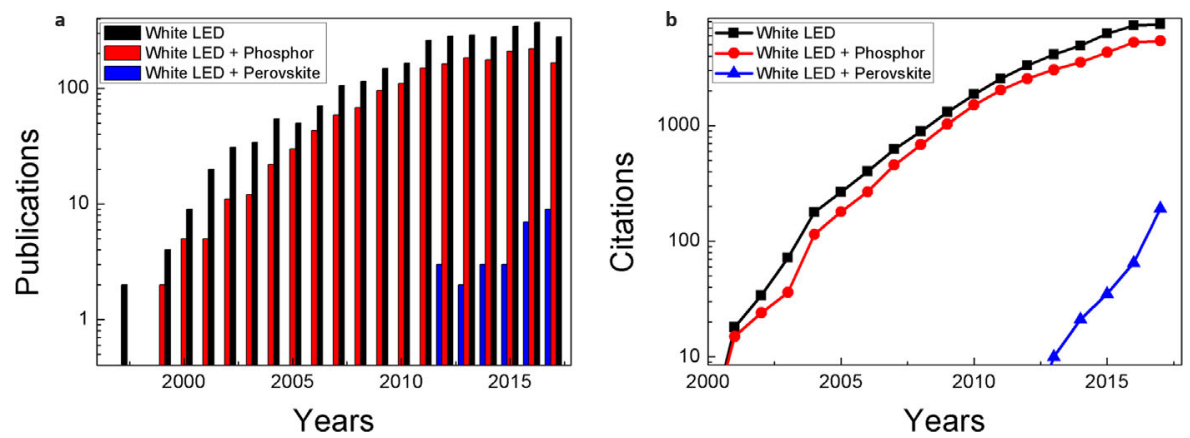

Figure 1. Statistical data of (a) publications and (b) citations about the last 20 years. 
properties; and third, their use as a color conversion layer in WLED configurations. Finally, a conclusive perspective will be presented concerning the challenges and future prospects of halide perovskites.

\section{Preparation of Halide Perovskites}

Halide perovskites, in general, contain $\left[\mathrm{BX}_{6}\right]^{4-}\left(\mathrm{B}: \mathrm{Pb}^{2+}\right.$ or $\mathrm{Sn}^{2+}$ or $\mathrm{Ge}^{2+}$ ) as counter ions, having an octahedral arrangement around a central cation. The cations, either organic $\left(\mathrm{MA}^{+}\right.$or $\mathrm{FA}^{+}$) or inorganic $\left(\mathrm{Cs}^{+}\right)$, are located between the large spaces of anionic octahedron sites (Figure 2a). The polymorphs of this crystal structure have cubic, tetragonal, and orthorhombic lattices in the bulk form. ${ }^{[44]}$ Note that merely an orthorhombic phase is reported for QDs. ${ }^{[57,58]}$ The band gap of related perovskite crystals varies based on the type of cation. For instance, $\mathrm{MAPbI}_{3}$ has $E_{\mathrm{g}} \approx 1.50-1.61 \mathrm{eV}, \mathrm{FAPbI}_{3}$ has $E_{\mathrm{g}} \approx 1.47-$ $1.55 \mathrm{eV}$, and $\mathrm{CsPbI}_{3}$ has $\approx 1.67-1.73 \mathrm{eV}^{[59]}$ Therefore, it is important to select the appropriate halide perovskite(s) depending on the targeted application: solar cell, LED, laser, transistor, etc.

\subsection{Organometallic Halide Perovskites}

Various preparation methods have been developed to synthesize organometallic halide perovskites as targeting novel potential applications, particularly to enhance the efficiency of both solar cells and LEDs or to improve their stability to be used in WLED. In frontier studies, halide perovskites were synthesized through mesoporous metal oxides, where the porosity allows the formation of perovskite crystals. ${ }^{[41,60-64]}$ Parallel to the advance of colloidal synthesis methods, it becomes possible to obtain bulk $^{[65-67]}$ or nano-structured ${ }^{[68-70]}$ organometallic perovskites from a solution.

In this context, this review focuses on the solution-based NC synthesis of these materials, which can be divided into two strategies. The first involves ligand-assisted re-precipitation. A highly polar solvent, such as DMF, is used to dissolve both alkylammonium halide and the lead halide source; then, the resulting solution mixture is injected into a poor solvent to trigger NC crystallization. For instance, Zhang et al. ${ }^{[71]}$ dissolved $\mathrm{PbBr}_{2}, \mathrm{MABr}, n$-octylamine, and oleic acid in DMF, and then dropped this solution with a fixed amount into toluene. The authors obtained $\mathrm{MAPbBr}_{3}$ quantum dots with $3.3 \mathrm{~nm}$ size and having $50-70 \%$ absolute quantum yields.

The second strategy is the ionic metathesis approach, which involves no polar solvent but rather various sources of cation, including alkyl-amines (similar to using Cs-oleate as a $\mathrm{Cs}^{+}$ source in the case of synthesizing all-inorganic perovskites). As an example, Vybornyi et al. ${ }^{[6]}$ used oleic acid (OA) containing methylamine solution in tetrahydrofuran (THF), injecting it into a solution of $\mathrm{PbX}_{2}$ containing an oleylamine (OAm)-OA-ODE mixture. The resulting solution showed fast crystallization occurring in seconds, proving that the authors successfully obtained $\mathrm{MAPbX}_{3}\left(\mathrm{X}=\mathrm{Br}^{-}\right.$and $\left.\mathrm{I}^{-}\right)$nanocrystals, with various morphologies of cubes, wires, and platelets, by controlling the volumetric ratio of OAm and OA. For instance, in the case of $\mathrm{MAPbI}_{3}$, the authors obtained nanocubes by employing the particular OAm/OA ratio of 0.2:0.8, nanoplatelets from 0.7:0.12, nanowires from 0.6:0.7, and quantum dots from 0.5:1.5.

\subsection{All-Inorganic Halide Perovskites}

Similar to the fabrication of organometallic halide perovskite NCs, all-inorganic perovskite synthesis includes two main methods: hot injection and room-temperature recrystallization. ${ }^{[72]}$ In hot injection (Figure 2b), preheated Cs-oleate is injected as $\mathrm{Cs}^{+}$source into a solution mixture containing $\mathrm{PbX}_{2}$ and $\mathrm{OA}, \mathrm{OAm}$, and $\mathrm{ODE}$, at temperatures varying from 60 to $250^{\circ}$, under which decomposition of the complex takes place. ${ }^{[46,73,74]}$ The solution rapidly turns a greenish color, most probably due to the formation of bright green emission of NCs under daylight. The crystals can be then collected via centrifugation. This method allows for control of the size of the resulting $\mathrm{NC}$ by adjusting reaction time, temperature, and precursor concentrations. ${ }^{[75]}$ A typical sample with a nanocube shape is illustrated by the inset.

In the case of room temperature recrystallization (Figure 2c), similar to the organometallic halide synthesis, $\mathrm{CsX}$ and $\mathrm{PbX}_{2}$ are dissolved in a good solvent, such as DMF, in the presence of OA and OAm. Then, an aliquot of this mixture is dropped into a poor a
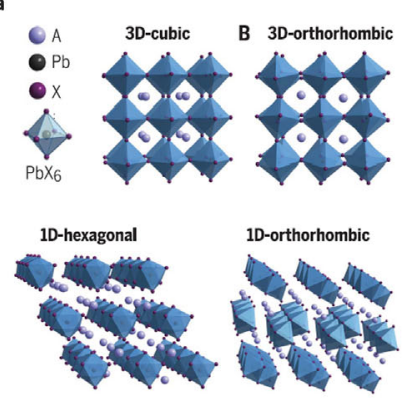

b

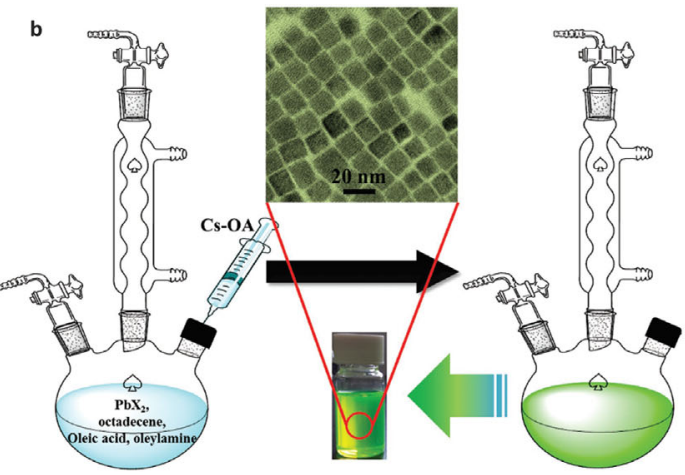

c

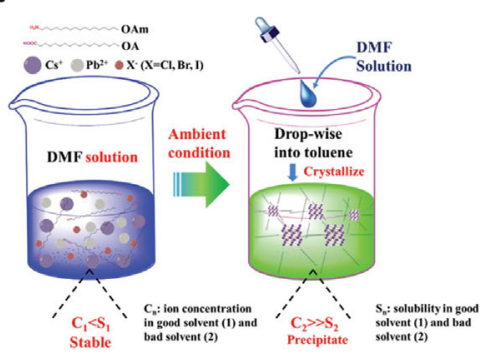

Figure 2. Schematic representation of (a) halide perovskite crystal structures, (b) hot injection method (TEM image of a typical sample is given at the inset), and (c) room-temperature recrystallization. a) Reproduced with permission. ${ }^{[4]}$ Copyright 2017 , The American Association for the Advancement of Science. b) Reproduced with permission. ${ }^{[72]}$ c) Reproduced with permission. ${ }^{[77]}$ 
solvent, such as toluene, causing a supersaturation and leading to fast crystallization, due to the solubility difference between DMF and toluene. ${ }^{[76,77]}$

Notice that the ligands OA and OAm are used during the synthesis of both organometallic and all-inorganic halide perovskites. These ligands can balance the charge between cations and anions. Therefore, by varying the chemical properties of these ligands or their ratio, one can tune the morphology of resulting NCs. ${ }^{[72,78-81]}$ For instance, Pan et al. ${ }^{[80]}$ showed that by varying the length of amine and acid chains and injection temperature, $\mathrm{CsPbBr}_{3}$ nanoplatelets and nanocubes with various sizes and quantum yields can be obtained. In the case of employing $\mathrm{OA}$ and $\mathrm{OAm}$, tuning the reaction temperature from 170 to $140^{\circ}$ leads to a change from nanocube to nanoplatelet, with sizes of 7.1-2.6 $\mathrm{nm}$ and with almost similar quantum yields of $\approx 86 \%$. On the other hand, by adjusting the amine chain length via replacing OAm with dodecylamine at the fixed temperature $170^{\circ}$, the authors were also able to change the morphology from nanocube to nanoplatelet, while reducing the size from 7.1 to $4.5 \mathrm{~nm}$ and the quantum yield from 87 to $51 \%$, respectively. Moreover, Tong et al. ${ }^{[82]}$ reported that $\mathrm{CsPbX}_{3}$ nanowires can be obtained from precursor powders by using OA and OAm through a single-step ultrasonication-assisted synthesis.

\section{Optical Characteristics of Halide Perovskite Materials}

One of the exceptional features of halide perovskites is the tunability of the emitting wavelength. In general, it can be achieved simply via anion-exchange reactions or via quantum confinement by adjusting the NC size. A number of studies reported in literature show the control over spectral features between 390 and $1050 \mathrm{~nm} .{ }^{[46,64,71,83-90]}$ Anion-exchange reactions depend on the halide ions of $\mathrm{X}$ that are used in the $\mathrm{ABX}_{3}$ structure, showing a blue shift when $\mathrm{Cl}^{-}$ions were employed, where $\mathrm{I}^{-}$shifts the resulting emission toward red.

In theoretical perspective, energy of the emitted photon from $\mathrm{CsPbX}_{3}$ can be related to the energy between conduction band minimum (CBM) and valence band maximum (VBM). Even though CBM was reported as being composed primarily of $\mathrm{Pb} 6 \mathrm{p}$ with minor halide $n \mathrm{p}$ orbitals, VBM contains an antibonding hybridization of $\mathrm{Pb} 6 \mathrm{~s}$ and $\mathrm{X} n \mathrm{p}$ orbitals, where the major contribution comes from the $n \mathrm{p}$ orbitals of the counter ion $\mathrm{X}^{\text {[91] }}$ In this sense, since halide ions possess different energy levels- $\mathrm{Cl}$ $(3 p), B r(4 p)$, and I (5p)-wavelength tuning is the natural outcome of the changing bandgap through shifting the VBM toward more positive potentials, with the decreasing energy of the $n$ p orbitals of $\mathrm{X}$ from $\mathrm{I}^{-}$to $\mathrm{Cl}^{-}$.

Furthermore, halide perovskite crystals can also be prepared using more than a single anion, i.e., $\mathrm{AB}\left(\mathrm{Cl}_{\mathrm{x}} \mathrm{Br}_{\mathrm{y}} \mathrm{I}_{1-\mathrm{x}-\mathrm{y}}\right)_{3}$, where the total ratio of these halide anions is equal to unity $(0 \leq x$, $y \leq 1$ ). Simply by adjusting the ratio of halide anions, the full spectrum can be covered from UV to infrared. ${ }^{[46,72,88,92]}$ Figure 3a shows the emission of the samples with various halide ions (or halide ion ratios) under UV light. Their registered PL and absorption-emission spectra are given in Figure 3 (b and c), which clearly verify the tunability of wavelength depending on the counter halide ions from UV to infrared.

Another parameter for the control over optical properties is quantum confinement. It shows the effect of particle size on its emission, and it can be related by

$E=\frac{\hbar^{2} \pi^{2}}{2 r^{2} m^{*}}+\left(E_{\mathrm{g}}-R_{\mathrm{y}}\right)$

where $r$ is the radius of the particle, $m^{*}$ is the reduced carrier mass, and $E_{\mathrm{g}}$ is the band gap energy; $R_{\mathrm{y}}=m^{*} e^{4} / 2 \varepsilon^{2} \hbar^{2}$ is the exciton binding energy including $\varepsilon$ as the dielectric constant, which can be used for both band-gap engineering and quantum yield improvement. In general, a critical parameter known as Bohr's radius $\left(a=\hbar^{2} \varepsilon^{\text {eff }} / m^{*} e^{2}\right)$, defined through Equation (1), is used to understand the degree of confinement for a given particle size. In the case of having particles much larger than $a$, the first term in Equation (1) drops, and the excited state of the particle becomes lower than the ground state (no confinement). However, the confinement appears when the particle size is smaller than $a$, since $E$ reaches larger values compared to $E_{\mathrm{g}}$. In such a case, the system starts to behave like a quantum well,
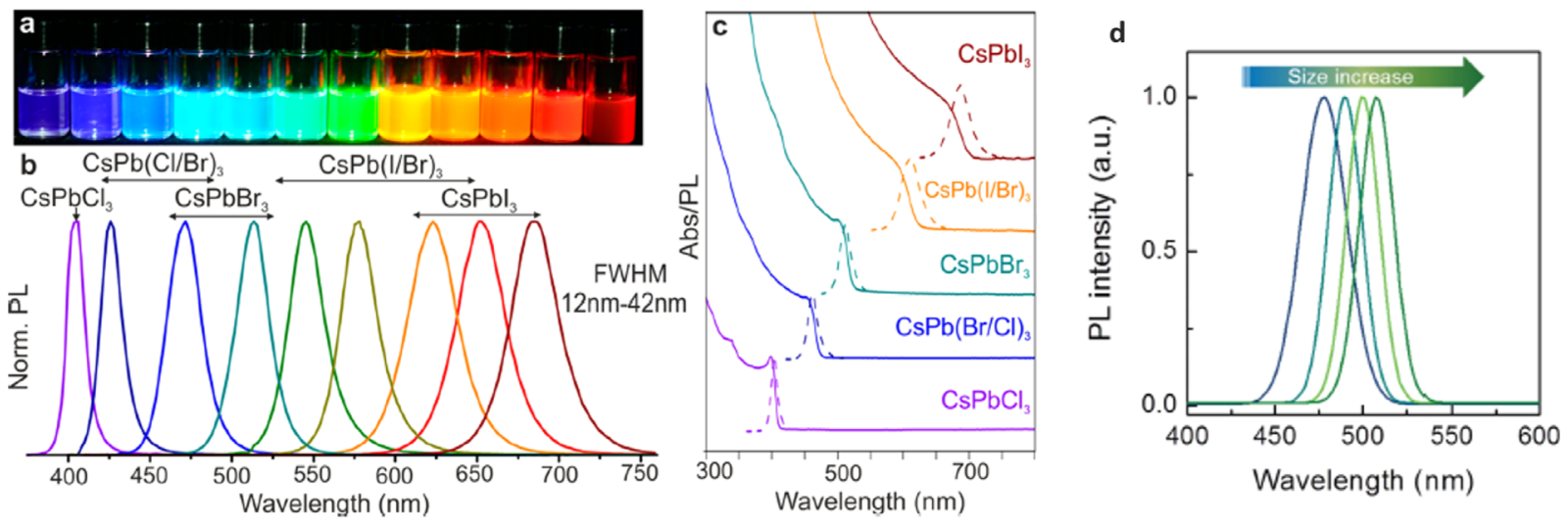

Figure 3. a) Halide perovskites with various anions (or anion ratio) under UV illumination, (b and c) collected PL and abs/PL spectra of related samples, respectively. a-c) Reproduced with permission. ${ }^{[46]}$ Copyright 2015, American Chemical Society. d) The size effect of perovskite NCs on the wavelength tunability. Reproduced with permission. ${ }^{[47]}$ 
showing a sharp distinction between excited states, leading to increased energy of excited states. This size effect is illustrated in Figure 3d.

As the size of perovskite NCs increases, a red shift takes place in the wavelength at almost $50 \mathrm{~nm}$. Moreover, Huang et al. ${ }^{[93]}$ reported that during the synthesis of $\mathrm{MAPbBr}_{3} \mathrm{NCs}$ via recrystallization, they obtained size-tunable band-gap by simply adjusting the temperature of the poor solvent. The authors found tuning emissions in the range of $475-520 \mathrm{~nm}$. High quantum yields of $74-94 \%$ were obtained following this method. Sizetunable band-gap can be achieved in the case of all-inorganic halide perovskites, too. For instance, Protesescu et al. ${ }^{[46]}$ synthesized $\mathrm{Cs} \mathrm{PbBr}_{3} \mathrm{NCs}$ with particle diameters ranging from 4 to $12 \mathrm{~nm}$, which were able to cover the spectral region of 410$700 \mathrm{~nm}$ with high quantum yields of $50-90 \%$, respectively. The authors calculated the Bohr radius of $\mathrm{CsPD}_{3}$ halide perovskites and found it to be $5 \mathrm{~nm}$ for $\mathrm{Cl}^{-}, 7 \mathrm{~nm}$ for $\mathrm{Br}^{-}$, and $12 \mathrm{~nm}$ for $\mathrm{I}^{-}$, which are demonstrably comparable in size with the perovskite crystals that they had synthesized. Recently, doping in perovskite crystals, particularly with $\mathrm{Mn}^{2+}$ ions, has become a new and active research era, which can serve as an alternative strategy to wavelength tuning in halide perovskites. ${ }^{\left[{ }^{94-97]}\right.}$ In such a case, $\mathrm{Pb}^{2+}$ ions are substituted with $\mathrm{Mn}^{2+}$ in the octahedron structure of $\left(\mathrm{PbX}_{6}\right)^{4-}$ under certain conditions, such as particular temperatures of medium or $\mathrm{Mn}^{2+}$ concentrations.

The instability of these halide perovskites ${ }^{[98,99]}$ is a major obstacle that needs to be overcome, because perovskites readily undergo chemical degradation and eventually optical loss. Allinorganic halide perovskites show better intrinsic stability compared to their organic counterparts, since they have higher thermal resistance $\left(>500^{\circ}\right)^{[100]}$ and better photostability. Nevertheless, these perovskite crystals still suffer from chemical instability against moisture, oxygen, and polar solvents such as water, acetone, ethanol, and even against perovskite crystals with different halide ions. For instance, in the last case, mixing halide perovskites with different halide ions result in anion-exchange reactions, which can cause shifts in the PL emission of individually incorporated halide perovskites into mixture. As a result, one obtains a floating PL emission from the mixture, which deteriorates the optical stability of WLED.
Various methods have been developed to improve the stability of halide perovskites. For instance, Wang et al. ${ }^{[101]}$ mixed mesoporous silica-of pore size $12-15 \mathrm{~nm}$-with green $\mathrm{Cs} \mathrm{PbBr}_{3}$ halide perovskite in a non-polar solvent, and found that this method is able to prevent anion-exchange reactions between green $\mathrm{CsPbBr}_{3}$ and red $\mathrm{CsPb}\left(\mathrm{Br}_{0.4} \mathrm{I}_{0.6}\right)_{3}$ when they mix in silicone resin (Figure 4a). In another method, Bhaumik et al. ${ }^{[102]}$ reported that they obtained a stable $\mathrm{MAPbBr}_{3}$ by growing a shell of octyl-ammonium lead bromide, which has a high band-gap over the $\mathrm{MAPbBr}_{3}$ (Figure 4b). This method of growing a wider band-gap shell over a lower band-gap core is also known as coreshell semiconducting nanocrystals. ${ }^{[103]}$ Further methods about improving the stability will be discussed in the next section while summarizing the WLED applications of halide perovskites.

\section{Use of Halide Perovskites in WLED Applications}

\subsection{Blue LED + YAG:Ce ${ }^{3+}+$ Halide Perovskite}

In YAG: $\mathrm{Ce}^{3+}$-based WLED applications, generated white light generally exhibits lower CRI, since the resulting spectrum lacks the red component. To improve CRI, red phosphors, particularly ones with narrow FWHM, can be integrated into the system. ${ }^{[104]}$ In this sense, red halide perovskite crystals can be used to improve CRI and reduce CCT by integrating them into traditional phosphor-converted WLED applications. Following this strategy, Zhou et al. ${ }^{[105]}$ fabricated red-emitting perovskites $\mathrm{NCs}$ by alloying $\mathrm{CsPbI}_{3}$ with $\mathrm{Br}^{-}$(leading to $\mathrm{CsPbBr}_{1.2} \mathrm{I}_{1.8}$ ), which has a better stability against moisture compared to $\mathrm{CsPbI}_{3}$. Using this alloyed red-emitting perovskite QDs in poly (methyl methacrylate) (PMMA)/chloroform solution, the authors covered the upper surface of a YAG-based WLED device using the spin coating method (Figure 5a). As a result, this WLED system showed CRI of 92, CCT of $4222 \mathrm{~K}$, and LE of $78.41 \mathrm{~lm} \mathrm{~W}^{-1}$, which is superior to a bare YAG-based WLED system (with CRI of 74, and CCT of $6713 \mathrm{~K}$ ).

Similarly, Zhou et al. ${ }^{[106]}$ also reported a promising red $\mathrm{CsPbBr}_{3-\mathrm{x}} \mathrm{I}_{\mathrm{x}}$ halide perovskite QDs used in a YAG:Ce ${ }^{3+}$-based WLED system. The optical properties of this red halide perovskite were examined to find the optimum value of $x$ reported as 2 ,

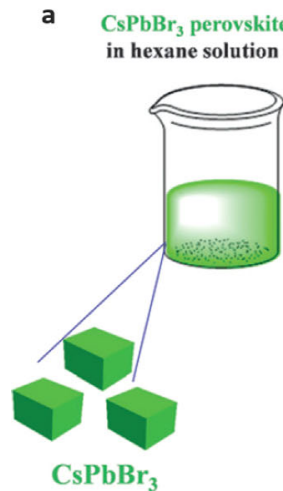

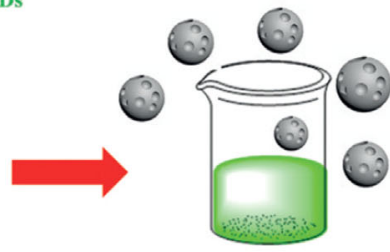

Mesoporous silica powder with pore size 12-14 $\mathrm{nm}$ mixed with $\mathrm{CsPBBr}_{3}$ perovskite QDs in hexane solution at room temperature

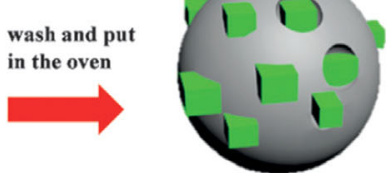

MP-CsPbBr 3 PQDs b

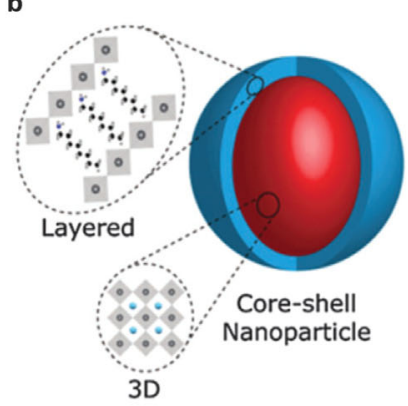

Figure 4. Different halide perovskite stabilization methods; (a) mixing with mesoporous silica and (b) growing shell of wider band-gap over halide perovskite NCs. a) Reproduced with permission. ${ }^{[101]}$ b) Reproduced with permission. ${ }^{[102]}$ Copyright 2016, Royal Society of Chemistry. 


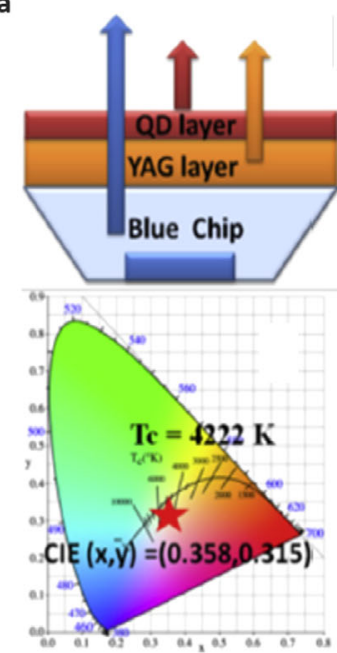

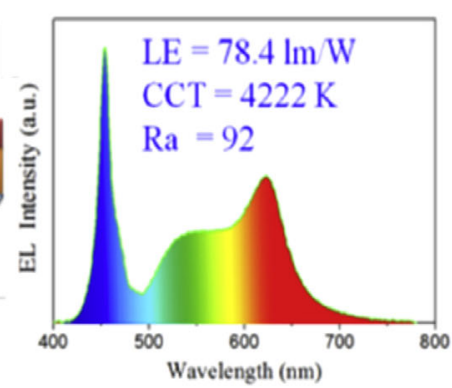

b

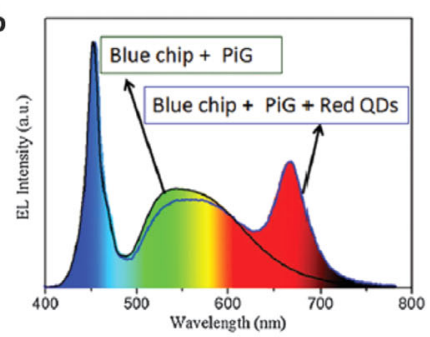

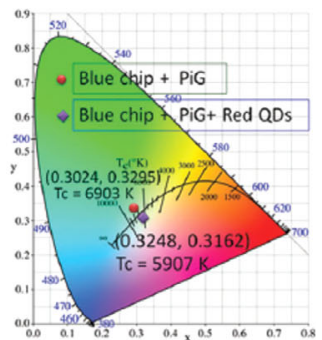
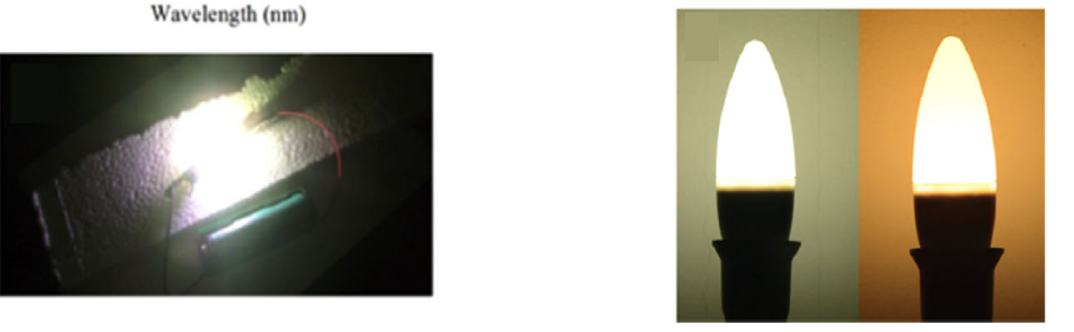

Figure 5. WLED applications of red halide perovskites integrated into the blue LED excited YAG:C $\mathrm{e}^{3+}$ phosphor, which are (a) directly coated on blue LED or (b) prepared in the form of PiG systems. a) Reproduced with permission. ${ }^{[105]}$ Copyright 2017, Elsevier. b) Reproduced with permission. ${ }^{[106]}$ Copyright 2016, Royal Society of Chemistry.

showing both high quantum yield and intensive luminescence. Then the authors embedded the optimized halide perovskite $\left(\mathrm{CsPbBr}{ }_{2}\right)$ into PMMA and deposited it on the upper surface of the YAG: $\mathrm{Ce}^{3+}$-based phosphor-in-glass (PiG) disk by using spin coating (Figure $5 \mathrm{~b}$ ). It was found that placing this color conversion layer over blue LED in a remote system produced the results CRI of 90, CCT of $5907 \mathrm{~K}$, and LE of $58 \mathrm{~lm} \mathrm{~W}^{-1}$, which are quite satisfactory and suggest that halide perovskites are promising materials for future WLED applications.

On the other hand, Song et al. ${ }^{[107]}$ argued that PMMA can cause degradation for these perovskites, and the authors offered ethyl cellulose as an alternative to PMMA. Two red-emitting $\mathrm{CsPb}\left(\mathrm{Br}_{0.4} \mathrm{I}_{0.6}\right)_{3}$ halide perovskite-embedded polymeric films were prepared, using ethyl cellulose and PMMA as matrix. The quantum yield of halide perovskite in the ethyl cellulose was reduced from 34.2 to $19.8 \%$, while the PMMA-based quantum yield reduced from 34.9 to $9.5 \%$ after $200 \mathrm{~h}$ dipping time of the films in water. Stabilization of the perovskite materials against water was discovered to be superior compared to the PMMAbased sample, as it is the result of passivation characteristics of ethyl cellulose. Meanwhile, white color was obtained from the ethyl cellulose-based halide perovskite QDs integrated with the YAG: $\mathrm{Ce}^{3+}$-blue LED system, showing CRI of 90.3, CCT of $3897.9 \mathrm{~K}$, and LE of $46.45 \mathrm{~lm} \mathrm{~W}^{-1}$ under $20 \mathrm{~mA}$ forward-bias current. Even though PMMA is able to keep the bright luminescence of QDs due to its high transparency, it does not show a significant stability improvement against UV exposure nor against photo-oxidation, since the oxygen diffusion coefficient of PMMA is relatively high. ${ }^{[108]}$

To provide further stability for halide perovskite QDs, Di et al. ${ }^{[109]}$ coated these QDs with mesoporous silica. They showed that all-inorganic perovskites can keep their optical performance for months under air atmosphere. As a WLED application, the authors used two systems with two different chemistries of halide perovskites: $\mathrm{CsPbBr}_{3} /$ silica as green-emitting, and $\mathrm{CsPb}\left(\mathrm{Br}_{0.4} \mathrm{I}_{0.6}\right)_{3} /$ silica as red-emitting conversion layers. In the first system, they stacked red-emitting perovskite QDs/silica, blended with organic paste film, on a PiG plate over a blue LED. In the second system, green-emitting and red-emitting perovskite QD/silica powders with blue LED were combined. The authors reported that the former strategy exhibits CRI of 92, CCT of $5198 \mathrm{~K}$, and LE of $75.2 \mathrm{~lm} \mathrm{~W}^{-1}$, while the latter shows CRI of 82 , CCT of $5853 \mathrm{~K}$, and LE of $14.1 \mathrm{~lm} \mathrm{~W}^{-1}$. Evidently, the first strategy performed better than the second one. The authors then optimized the white light generation in terms of the concentration of red perovskite, and obtained CRI of 92, CCT of $4718 \mathrm{~K}$, and $\mathrm{LE}$ of $56 \mathrm{~m} \mathrm{~W}^{-1}$ under $20 \mathrm{~mA}$ driving current for the particular concentration.

In another approach, same-halide perovskite QDs with various $x$ of $\mathrm{CsPbBr}_{3-\mathrm{x}} \mathrm{I}_{\mathrm{x}}$ were used in the form of liquid-type, which aims to keep the related quantum dot solution in liquid phase while protecting them from drying. For instance, Sher at al. ${ }^{[110]}$ used a glass material to keep the QD solution in liquid form, and the authors showed that the liquid-type QD structure can stabilize the QDs against the environment while providing high and reliable CRI. Moreover, the authors found that this method can also improve the efficiency of QDs and reduce thermal effects. In the case of halide perovskites, Bi et al. ${ }^{[111]}$ prepared red $\mathrm{CsPb}(\mathrm{Br} / \mathrm{I})_{3}$ liquid-type QDs and combined them with the traditional yellow phosphor YAG: $\mathrm{Ce}^{3+}$ as color conversion layers, to fabricate warm WLED pumped with a blue LED. As a result of this combination, luminous efficiency of $84.71 \mathrm{~m} \mathrm{~W}^{-1}$, CRI of 89 , and CCT range of 2853-11.068 $\mathrm{K}$ were achieved, depending on the QD concentration, while maintaining its initial quantum efficiency.

\subsection{Blue LED + Halide Perovskite}

Apart from integrating red perovskite QDs into YAG:Ce ${ }^{3+}$-based pc-WLEDs, one can also replace the traditional YAG: $\mathrm{Ce}^{3+}$ yellow phosphor with perovskites such as green-emitting $\mathrm{CsPbr}_{3}$. In 
this context, Li et al. ${ }^{[77]}$ used all-inorganic red and green halide perovskite QDs in a PMMA matrix, and cast them as separate layers over blue LED. Then, by simply changing the red and green QD component ratio, CCT was tuned between 2500 and $11500 \mathrm{~K}$. The resulting CIE color coordinate was optimized to $(0.33,0.30)$, which is very close to the standard coordinates of $(0.33,0.33)$ as white color.

In an another case, Pathak et al. ${ }^{[112]}$ first reported that, by varying the ratio of OA and MA in the synthesis of perovskite, the size of the crystals can be controlled to a 5-10 nm length scale of resulting crystals. By substituting MA with OA, the authors observed that PL quantum yield was enhanced from 20 to $36 \%$ (from MA only to a 0.6 OA:0.4 MA molar ratio). However, further increase in the molar ratio results in a decreased quantum yield (18\% for 0.9 OA:0.1 MA molar ratio). Next, the authors blended PS with the mixture of blue, green, red, and emitting crystals at intermediate regions, from 410 to $770 \mathrm{~nm}$ (which can be obtained via mixing $\mathrm{I}^{-} / \mathrm{Br}^{-}$and $\mathrm{Br}^{-} / \mathrm{Cl}^{-}$halides), and they found that the mixture covered a visible range (Figure 6a). Moreover, the authors fabricated PS/perovskite composite films by separately embedding (0.3 OA:0.7 MA) $\mathrm{PbBr}_{3}$ emitting at $520 \mathrm{~nm},(0.3 \mathrm{OA}: 0.7 \mathrm{MA}) \mathrm{Pb}\left(\mathrm{I}_{0.66} \mathrm{Br}_{0.34}\right)_{3}$ emitting at $678 \mathrm{~nm}$, and (0.3 OA:0.7 MA) $\mathrm{PbI}_{3}$ emitting at $775 \mathrm{~nm}$ in the PS matrix, the results of which are presented in Figure 6b (under UV illumination). By stacking these films over the blue LED chip, the authors generated white light (Figure $6 c$ ), which has the optical features CRI of 86 and CCT of $5229 \mathrm{~K}$.

Meyns et al. ${ }^{[113]}$ suggested that introducing poly(maleic anyhdride-alt-1-octadenece) (PMA) during the synthesis of halide perovskites can increase their quantum yield while stabilizing their optical features, by protecting their surface and preventing them from aggregating. Two perovskites, emitting in green $\mathrm{CsPbBr}_{3}$-PMA and emitting in red $\mathrm{CsPbBr}_{1.6} \mathrm{I}_{1.4}-\mathrm{PMA}$, were prepared and employed in a stacking configuration over blue LED. It was found that CRI of 72.4 and CCT of $3665 \mathrm{~K}$ were initially obtained, and then-due to degradation of the red component-CRI was reduced to 66.9 and CCT increased to $9300 \mathrm{~K}$ after $5 \mathrm{~min}$, even in the presence of PMA.

Wei et al. ${ }^{[14]}$ packed all-inorganic perovskites into crosslinked polystyrene (PS) beads in the form of perovskite QD@PS, by using the swelling-shrinking strategy. The authors were able to stabilize perovskite QDs against water, acid-aqueous solution, and alkali-aqueous solution, while maintaining their high luminescence. They then fabricated WLED using blue LED and a mix of green $\mathrm{CsPbBr}_{3} @ P S$ and red $\mathrm{CsPb}\left(\mathrm{Br}_{0.4} \mathrm{I}_{0.6}\right)_{3} @ \mathrm{PS}$ halide perovskites. The spectrum of the prepared WLED was found to possess three individual emission signals, which indicate that an ion-exchange reaction was also prevented between green and red halide perovskites. In other words, green and red halide perovskites were able to maintain their corresponding solid state PL spectra even after they were mixed. With this system, the authors found that the generated white light has color coordinates of $(0.31,0.30)$.

In the case of organometallic halide perovskites, Zhang et al. ${ }^{[71]}$ blended halide perovskite possessing organic cation MA with a PMMA/chloroform solution, combining it with a red phosphor KSF dispersed in a silicone gel, as separate layers, over a blue LED. The resulting WLED was found to have a luminous
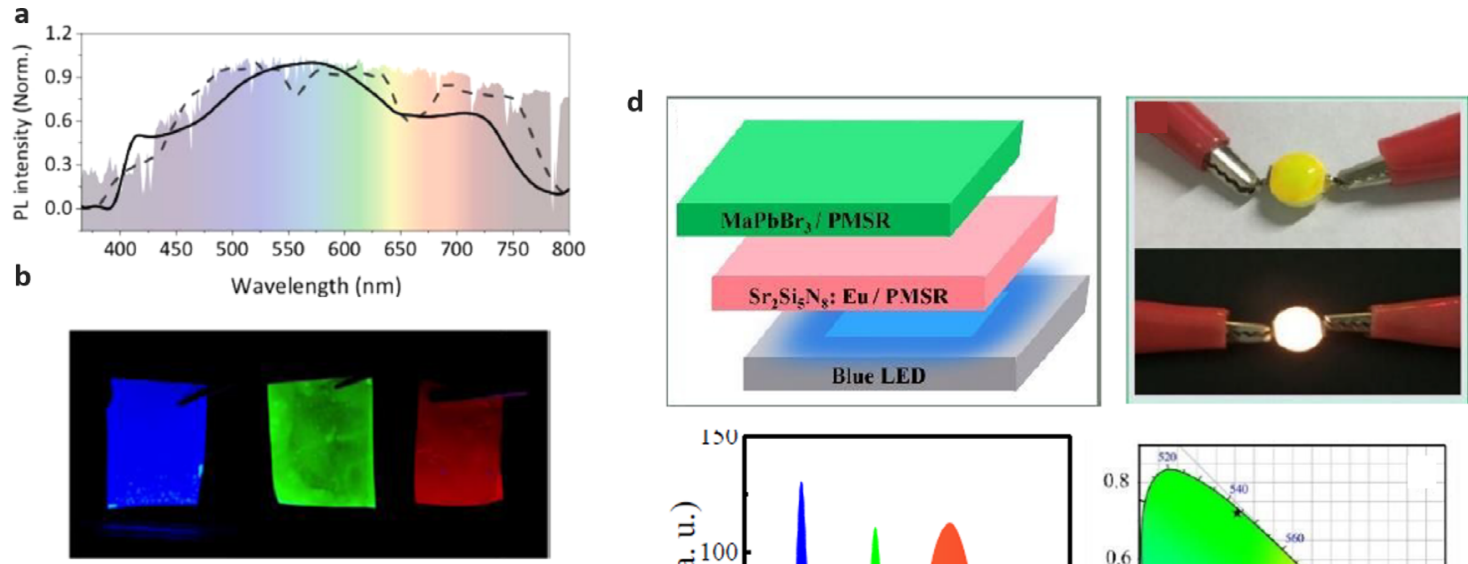

c
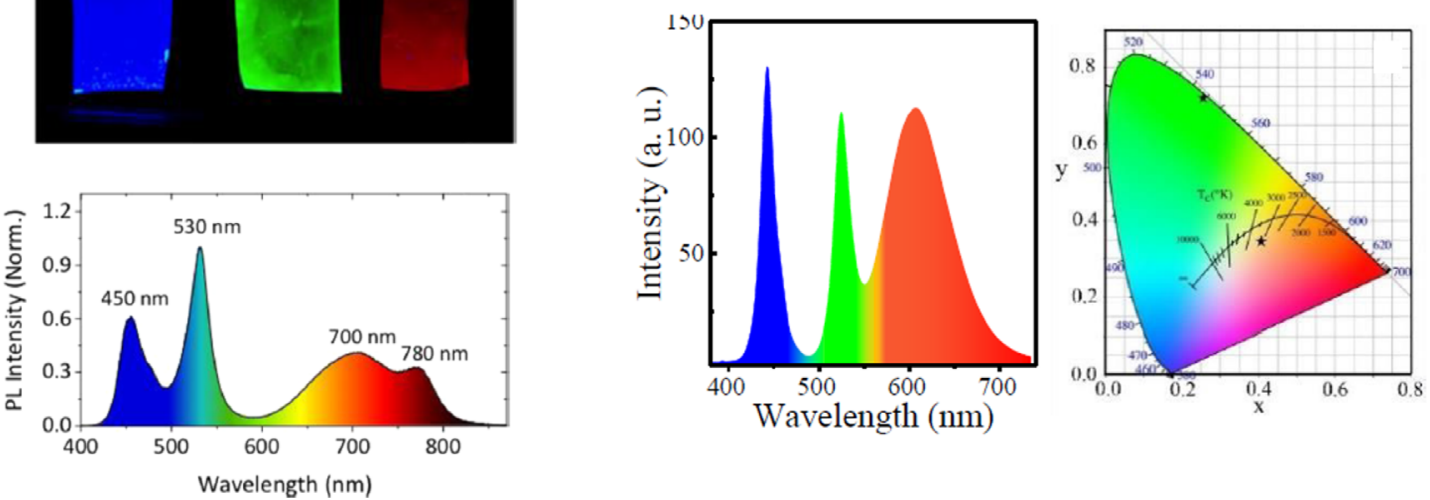

Figure 6. a) Spectrum of the mixture of blue, green, and red halide perovskites. Parts ( $b$ and c) present the appearance of blue, green, and red halide perovskites under UV illumination, and their related spectrum after stacking them onto the blue LED, respectively. a-c) Reproduced with permission. ${ }^{[12]}$ Copyright 2015, American Chemical Society. d) WLED fabricated via stacking the green emitting halide perovskite with a red phosphor over blue LED. Reproduced with permission. ${ }^{[16]}$ Copyright 2017, Royal Society of Chemistry. 
efficiency of $48 \mathrm{~lm} \mathrm{~W}^{-1}$ and color coordinates of $(0.33,0.27)$. The authors pointed out that casting the $\mathrm{MAPbBr}_{3} / \mathrm{PMMA}$ over a blue LED, painted with a KSF silicone gel, shows superior performance compared to the CdSe-based LEDs in terms of color rendition. ${ }^{[115]}$

Similarly, Wang et al. ${ }^{[116]}$ used two commercial silicone resins to prepare stable green organometallic halide perovskite $\mathrm{MAPbBr}_{3}$ nanocomposites (Figure 6d). Among these, the QDs prepared with phenyl methyl silicone resin (PMSR) was found to exhibit better stability against UV, water, and thermal than the QDs prepared with the silicone sealant Dow Corning 937 (SSDC). The authors then fabricated a WLED by using green-emissive PMSR/QD and red-emissive nitride phosphor PMSR $/ \mathrm{Sr}_{2} \mathrm{Si}_{5} \mathrm{~N}_{8}: \mathrm{Eu}^{3+}$ composite films as separate layers over a blue LED. They obtained CCT of $3100 \mathrm{~K}$ and color coordinates of $(0.402,0.348)$, and the highest quantum yield of $62 \%$ was obtained.

As another example, Ma et al. ${ }^{[117]}$ used green emitting $\mathrm{CsPbr}_{3}$ halide perovskites that were synthesized in situ in the presence of PMMA via a microfluidic-spinning microreactor. This synthesis method of perovskite by in situ endowed great PL stability against water moisture and UV radiation, while the use of a microfluidic-spinning microreactor allowed a scale-up fabrication. For WLED application, the authors embedded the mixture of $\mathrm{CsPbBr}_{3} / \mathrm{PMMA}$ and emitting CdSe QD into a UVcurable adhesive, and then blue LED was encapsulated with this film to generate white light. They reported that the resulting white light possessed CRI of 89.2 with color coordinates of $(0.3413,0.3329)$ under $350 \mathrm{~mA}$ operation. Apart from polymers, perovskites can be prepared by incorporating them into microcrystals similar to QDs embedded in inorganic salts, which can lead to enhancement of the photo and chemical stabilities. $^{[118-121]}$

Using this strategy, $\mathrm{Xu}$ et al. ${ }^{[122]}$ incorporated halide perovskites into carboxybenzene (CB) crystals, and found that mixing halide perovskites with $\mathrm{CB}$ enhances the stability of perovskite QDs against moisture and blue light while keeping its PL properties. Furthermore, they prepared a WLED device composed of the mixture of blue LED with green-emitting $\mathrm{CsPbBr}_{3}-\mathrm{CB}$ and red-emitting $\mathrm{CsPb}\left(\mathrm{Br}_{0.4} \mathrm{I}_{0.6}\right)_{3}$-CB. They observed that anion-exchange reactions can be prevented due to the presence of CB, and they obtained color coordinates of $(0.41$, 0.37 ), which shows only a $7 \%$ reduction in PL intensity after $30 \mathrm{~h}$ of continuous illumination.

\subsection{UV LED + Halide Perovskite}

Fabrication of WLED using UV LED chip requires three main RGB colors to be generated under UV illumination. In this context, halide perovskites are suitable pigments to use as color conversion layers. These materials can be excited by UV and they cover the visible spectrum. Zhang et al. ${ }^{[123]}$ reported mixing of organic cations MA and FA in the particular ratios of 1:1 for blue and 4:1 for green emissions. Single-cation FA was used to produce red emission. All these materials having blue, green, and red emission were dissolved in PMMA/chloroform solution and then blended with thermocurable silicone resin. As a WLED application, a UV LED chip was coated separately with halide perovskite composite films, and results of CRI of 85 and luminous efficiency of $40.21 \mathrm{~m} \mathrm{~W}^{-1}$ were obtained (Figure 7).

Similarly, Palazon et al. ${ }^{[124]}$ prepared color conversion layers either by involving solely all-inorganic halide perovskites for all colors or by replacing the red color with non-perovskite emitters, such as Cu-In-Zn-S $(\mathrm{CIZS})^{[125]}$ or giant-shell CdSe/ CdS nanocrystals, ${ }^{[126]}$ and placed them over a $365 \mathrm{~nm}$ UV LED chip. In the case of all-inorganic halide perovskites, they colloidally synthesized all colors from the two main perovskites $\mathrm{CsPbBr}_{3}$ and $\mathrm{CsPbI}_{3}$ which differ in morphology. The $\mathrm{Cs} \mathrm{PbBr}_{3}$ nanocubes and nanoplatelets emit blue and green; $\mathrm{CsPbI}_{3}$ nanocubes and nanosheets emit red and orange. Apart from the instability observed for the perovskite mixture due to anionexchange reactions, $\mathrm{CsPbI}_{3}$ suffered also from the intrinsic instability that causes serious PL degradation, particularly against irradiation. ${ }^{[127]}$ This causes a lower overall efficiency
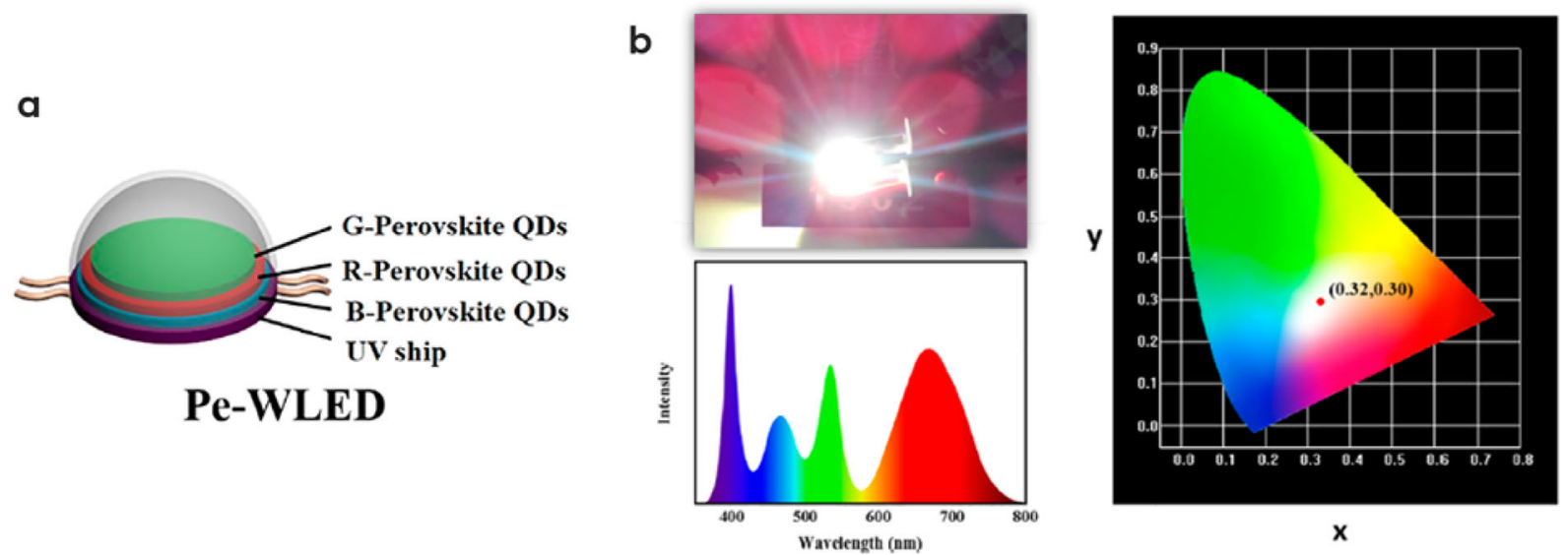

Figure 7. a) Schematic representation of WLED prepared using halide perovskites over UV LED chip and (b) resulting white light generation. Reproduced with permission. ${ }^{[123]}$ Copyright 2017, American Chemical Society. 
observed in the stacking case of perovskites $(1.19 \mathrm{Cd}$ at the excitation power of $800 \mathrm{~mW}$ ). In the case of non-perovskite red emitters, the authors mixed blue-green-emitting $\mathrm{CsPbBr}_{3}$ nanocubes-nanoplatelets with CIZS and CdSe/CdS, and obtained $x=0.31467 ; y=0.34251$; CCT $=6317 \mathrm{~K}$ from CIZS, $x=0.32396 ; y=0.35315$; CCT $=5856 \mathrm{~K}$ from the CdSe $/ \mathrm{CdS}$ based solution. White light is obtained in all approaches with tunable CCT; among those, the hybrid approach involving $\mathrm{CdSe} / \mathrm{CdS}$ nanocrystals showed very high stability upon continuous illumination at high power.

\section{Conclusion and Outlook}

WLED applications demand energy-efficient devices satisfying high CRI, tunable CCT, and high luminous flux, along with low cost. The last two decades of WLED-related studies indicate that phosphor studies have already begun to level off, most probably due to reaching the saturation point in terms of new phosphor discoveries or their optimization. In recent years, halide perovskites have attracted great attention, since they are able to provide the desired optical features with high quantum yields. However, instability against environmental conditions, such as humidity and polar solvents, still remains an issue. The optical features of these materials (i.e., their high quantum yield) have to be maintained-or at least the optical loss has to be minimized-after integrating with polymers such as silicone resin, because of the quenching effect of macromolecules through surface interactions and/or the aggregation of molecules. Nevertheless, halide perovskites are new, hotly debated, and promising materials for WLED applications. They appear to be a strong alternative to phosphors, and will lead to a significant rise in the number of WLED-related studies. Along with the studies enriched with novel pigment materials for instance perovskites in this overview, the near future of solid state lighting may focus on replacing LEDs with laser diodes to enhance the optical performance of the white light.

\section{Abbreviations}

$C C T$, correlated color temperature; $C R I$, color rendering index; $F A$, formamidinium; LE, luminous efficiency; LED, light emitting diode; $M A$, methylammonium; NC, nanocrystal; OA, oleic acid; OAm, oleylamine; pcWLED, phosphor converted white LED; QDs, quantum dots; $\mathrm{X}^{-}$, halide anion; YAG: $\mathrm{Ce}^{3+}$, cerium doped yttrium aluminum garnet.

\section{Acknowledgment}

The manuscript was written through contributions of all authors. All authors have given approval to the final version of the manuscript. This work was supported by both "Outstanding Young Investigator" grant of the Turkish Academy of Sciences (TÜBA-GEBIP 2013).

\section{Conflict of Interest}

The authors declare no conflict of interest.

\section{Keywords}

down conversion, halide perovskites, phosphor-converted white light emitting diode, solid state lighting, white light

Received: February 13, 2018

Revised: March 14, 2018

Published online: May 18, 2018

[1] E. F. Schubert, J. K. Kim, H. Luo, J. Xi, Rep. Prog Phys. 2006, 69, 3069.

[2] R. Haitz, J. Y. Tsao, Optik \& Photonik 2011, 6, 26.

[3] D. A. Steigerwald, J. C. Bhat, D. Collins, R. M. Fletcher, M. O. Holcomb, M. J. Ludowise, P. S. Martin, S. L. Rudaz, IEEE J. Select. Top. Quantum Electron. 2002, 8, 310.

[4] A. Kitai, Materials for Solid State Lighting and Displays. John Wiley \& Sons, Hoboken, NJ, USA 2017.

[5] J. Shang, C. Cong, Z. Wang, N. Peimyoo, L. Wu, C. Zou, Y. Chen, X. Y. Chin, J. Wang, C. Soci, Nat. Commun. 2017, 8, 543.

[6] J. Cho, J. H. Park, J. K. Kim, E. F. Schubert, Laser Photon. Rev. 2017, 11,1600147

[7] I. L. Azevedo, M. G. Morgan, F. Morgan, Proc. IEEE 2009, 97, 481.

[8] T. M. Katona, P. M. Pattison, S. Paolini, Annu. Rev. Chem. Biomol. Eng. 2016, 7, 263.

[9] J. Y. Tsao, H. D. Saunders, J. R. Creighton, M. E. Coltrin, J. A. Simmons, J. Phys. D: Appl. Phys. 2010, 43, 354001.

[10] https://energy.gov/eere/ssl/ssl-forecast-report.

[11] S. Muthu, F. J. Schuurmans, M. D. Pashley, IEEE J. Select. Top. Quantum Electron. 2002, 8, 333.

[12] A. Žukauskas, R. Vaicekauskas, M. Shur, Opt. Express 2010, 18, 2287.

[13] Z. Xia, Z. Xu, M. Chen, Q. Liu, Dalton Trans. 2016, 45, 11214.

[14] C. C. Lin, R.-S. Liu, J. Phys. Chem. Lett. 2011, 2, 1268.

[15] N. C. George, K. A. Denault, R. Seshadri, Annu. Rev. Mater. Res. 2013, 43, 481.

[16] L. Wang, R.-J. Xie, T. Suehiro, T. Takeda, N. Hirosaki, Chem. Rev. 2018, 118, 1951.

[17] Y. K. Mishra, R. Adelung, Mater. Today 2017, ISSN: 1369-7012, https://doi.org/10.1016/j.mattod.207.11.003.

[18] I. Tiginyanu, L. Chimpu, J. Gröttrup, V. Postolache, M. Mecklenburg, M. A. Stevens-Kalceff, V. Ursaki, N. Payami, R. Feidenhansl, K. Schulte, Sci. Rep. 2016, 6, 32913.

[19] A. Schuchardt, T. Braniste, Y. K. Mishra, M. Deng, M. Mecklenburg, M. A. Stevens-Kalceff, S. Raevschi, K. Schulte, L. Kienle, R. Adelung, Sci. Rep. 2015, 5, 8839.

[20] V. Kumar, O. Ntwaeaborwa, T. Soga, V. Dutta, H. Swart, ACS Photon. 2017, 4, 2613.

[21] G. Wegner, M. M. Demir, M. Faatz, K. Gorna, R. Munoz-Espi, B. Guillemet, F. Gröhn, Macromol. Res. 2007, 15, 95.

[22] M. M. Demir, G. Wegner, Macromol. Mater. Eng. 2012, 297, 838.

[23] S. Ye, F. Xiao, Y. Pan, Y. Ma, Q. Zhang, Mater. Sci. Eng.: R: Rep. 2010, 71, 1.

[24] S. C. Allen, A. J. Steckl, Appl. Phys. Lett. 2008, 92, 143309.

[25] N. Narendran, Y. Gu, J. Freyssinier-Nova, Y. Zhu, Phys. Status Solidi (a) 2005, 202, R60

[26] G. Li, Y. Tian, Y. Zhao, J. Lin, Chem. Soc. Rev. 2015, 44, 8688.

[27] T. Güner, D. Köseoğlu, M. M. Demir, Opt. Mater. 2016, 60, 422.

[28] C. C. Lin, A. Meijerink, R.-S. Liu, J. Phys. Chem. Lett. 2016, 7, 495.

[29] T. Ogi, A. B. D. Nandiyanto, K. Okino, F. Iskandar, W.-N. Wang, E. Tanabe, K. Okuyama, ECSJ. Solid State Sci. Technol. 2013, 2, R91.

[30] T. Güner, U. Şentürk, M. M. Demir, Opt. Mater. 2017, 72, 769.

[31] C.-F. Lai, J.-S. Li, C.-W. Shen, ACS Appl. Mater. Interfaces 2017, 9, 4851.

[32] C. C. Stoumpos, M. G. Kanatzidis, Accounts Chem. Res. 2015, 48, 2791. 
[33] V. M. Goldschmidt, Naturwissenschaften 1926, 14, 477.

[34] B. Saparov, D. B. Mitzi, Chem. Rev. 2016, 116, 4558.

[35] H. L. Wells, Z. anorg. allg. Chem. 1893, 3, 195.

[36] C. K. Møller, Nature 1958, 182, 1436.

[37] D. Weber, Z. Naturforsch. B 1978, 33, 1443.

[38] D. Mitzi, K. D. Karlin (editors), Progress in Inorganic Chemistry, John Wiley \& Sons, New York 1999.

[39] S. Bai, Z. Yuan, F. Gao, J. Mater. Chem. C 2016, 4, 3898.

[40] Q. Lin, A. Armin, R. C. R. Nagiri, P. L. Burn, P. Meredith, Nat. Photon. 2015, 9, 106.

[41] A. Kojima, K. Teshima, Y. Shirai, T. Miyasaka, J. Am. Chem. Soc. 2009, 131, 6050.

[42] M. A. Green, A. Ho-Baillie, H. J. Snaith, Nat. Photon. 2014, 8, 506.

[43] H. J. Snaith, J. Phys. Chem. Lett. 2013, 4, 3623.

[44] M. V. Kovalenko, L. Protesescu, M. I. Bodnarchuk, Science 2017, $358,745$.

[45] J.-P. Correa-Baena, M. Saliba, T. Buonassisi, M. Grätzel, A. Abate, W. Tress, A. Hagfeldt, Science 2017, 358, 739.

[46] L. Protesescu, S. Yakunin, M. I. Bodnarchuk, F. Krieg, R. Caputo, C. H. Hendon, R. X. Yang, A. Walsh, M. V. Kovalenko, Nano Lett. 2015, 15, 3692.

[47] J. Song, J. Li, X. Li, L. Xu, Y. Dong, H. Zeng, Adv. Mater. 2015, 27, 7162.

[48] H. Huang, L. Polavarapu, J. A. Sichert, A. S. Susha, A. S. Urban, A. L. Rogach, NPG Asia Mater. 2016, 8, e328.

[49] V. A. Hintermayr, A. F. Richter, F. Ehrat, M. Döblinger, W. Vanderlinden, J. A. Sichert, Y. Tong, L. Polavarapu, J. Feldmann, A. S. Urban, Adv. Mater. 2016, $28,9478$.

[50] Y. F. Ng, S. A. Kulkarni, S. Parida, N. F. Jamaludin, N. Yantara, A. Bruno, C. Soci, S. Mhaisalkar, N. Mathews, Chem. Commun. 2017, 53, 12004.

[51] B. R. Sutherland, E. H. Sargent, Nat. Photon. 2016, 10, 295.

[52] T. Güner, G. Topçu, U. Savacı, A. Genç, S. Turan, E. Sari, M. M. Demir, Nanotechnology 2018, 29, 135202.

[53] P. J. Cegielski, S. Neutzner, C. Porschatis, H. Lerch, J. Bolten, S. Suckow, A. R. S. Kandada, B. Chmielak, A. Petrozza, T. Wahlbrink, Opt. Express 2017, 25, 13199.

[54] Q. A. Akkerman, M. Gandini, F. Di Stasio, P. Rastogi, F. Palazon, G. Bertoni, J. M. Ball, M. Prato, A. Petrozza, L. Manna, Nat. Energy 2017, 2, 16194.

[55] D. Cortecchia, K. C. Lew, J.-K. So, A. Bruno, C. Soci, Chem. Mater. 2017, 29, 10088.

[56] P. Lova, D. Cortecchia, H. N. Swaha Krishnamoorthy, P. Giusto, C. Bastianini, A. Bruno, D. Comoretto, C. Soci, ACS Photon. 2018, 5, 867.

[57] P. Cottingham, R. L. Brutchey, Chem. Commun. 2016, 52, 5246.

[58] X. He, Y. Qiu, S. Yang, Adv. Mater. 2017, 29, 1700775.

[59] L. K. Ono, E. J. Juarez-Perez, Y. Qi, ACS Appl. Mater. Interfaces 2017, 9, 30197.

[60] J. Burschka, N. Pellet, S.-J. Moon, R. Humphry-Baker, P. Gao, M. K. Nazeeruddin, M. Grätzel, Nature 2013, 499, 316.

[61] B. Cai, Y. Xing, Z. Yang, W.-H. Zhang, J. Qiu, Energy Environ. Sci. 2013, 6, 1480.

[62] L. Etgar, P. Gao, Z. Xue, Q. Peng, A. K. Chandiran, B. Liu, M. K. Nazeeruddin, M. Grätzel, J. Am. Chem. Soc. 2012, 134, 17396.

[63] M. M. Lee, J. Teuscher, T. Miyasaka, T. N. Murakami, H. J. Snaith, Science 2012, 338, 643.

[64] J. H. Noh, S. H. Im, J. H. Heo, T. N. Mandal, S. I. Seok, Nano Lett. 2013, 13, 1764.

[65] H. Tsai, W. Nie, J.-C. Blancon, C. C. Stoumpos, R. Asadpour, B. Harutyunyan, A. J. Neukirch, R. Verduzco, J. J. Crochet, S. Tretiak, Nature 2016, 536, 312.

[66] Y. Liu, Z. Yang, D. Cui, X. Ren, J. Sun, X. Liu, J. Zhang, Q. Wei, H. Fan, F. Yu, Adv. Mater. 2015, 27, 5176.
[67] D. Shi, V. Adinolfi, R. Comin, M. Yuan, E. Alarousu, A. Buin, Y. Chen, S. Hoogland, A. Rothenberger, K. Katsiev, Science 2015, 347, 519.

[68] L. C. Schmidt, A. Pertegás, S. González-Carrero, O. Malinkiewicz, S. Agouram, G. Minguez Espallargas, H. J. Bolink, R. E. Galian, J. Pérez-Prieto, J. Am. Chem. Soc. 2014, 136, 850.

[69] O. Vybornyi, S. Yakunin, M. V. Kovalenko, Nanoscale 2016, 8, 6278.

[70] L. Protesescu, S. Yakunin, M. I. Bodnarchuk, F. Bertolotti, N. Masciocchi, A. Guagliardi, M. V. Kovalenko, J. Am. Chem. Soc. 2016, 138, 14202.

[71] F. Zhang, H. Zhong, C. Chen, X.-g. Wu, X. Hu, H. Huang, J. Han, B. Zou, Y. Dong, ACS Nano 2015, 9, 4533.

[72] X. Li, F. Cao, D. Yu, J. Chen, Z. Sun, Y. Shen, Y. Zhu, L. Wang, Y. Wei, Y. Wu, H. Zeng, Small 2017, 13, 1603996.

[73] A. Swarnkar, A. R. Marshall, E. M. Sanehira, B. D. Chernomordik, D. T. Moore, J. A. Christians, T. Chakrabarti, J. M. Luther, Science 2016, 354, 92.

[74] D. Zhang, S. W. Eaton, Y. Yu, L. Dou, P. Yang, J. Am. Chem. Soc. 2015, 137, 9230.

[75] Y. Bekenstein, B. A. Koscher, S. W. Eaton, P. Yang, A. P. Alivisatos, J. Am. Chem. Soc. 2015, 137, 16008.

[76] G. Li, H. Wang, T. Zhang, L. Mi, Y. Zhang, Z. Zhang, W. Zhang, Y. Jiang, Adv. Funct. Mater. 2016, 26, 8478.

[77] X. Li, Y. Wu, S. Zhang, B. Cai, Y. Gu, J. Song, H. Zeng, Adv. Funct. Mater. 2016, 26, 2435.

[78] Z. Liang, S. Zhao, Z. Xu, B. Qiao, P. Song, D. Gao, X. Xu, ACS Appl. Mater. Interfaces 2016, 8, 28824.

[79] Y. Hassan, Y. Song, R. D. Pensack, A. I. Abdelrahman, Y. Kobayashi, M. A. Winnik, G. D. Scholes, Adv. Mater. 2016, 28, 566.

[80] A. Pan, B. He, X. Fan, Z. Liu, J. J. Urban, A. P. Alivisatos, L. He, Y. Liu, ACS Nano 2016, 10, 7943.

[81] J. Shamsi, Z. Dang, P. Bianchini, C. Canale, F. Di Stasio, R. Brescia, M. Prato, L. Manna, J. Am. Chem. Soc. 2016, 138, 7240.

[82] Y. Tong, B. J. Bohn, E. Bladt, K. Wang, P. Müller-Buschbaum, S. Bals, A. S. Urban, L. Polavarapu, J. Feldmann, Angew. Chem. Int. Ed. 2017, 56, 13887.

[83] G. E. Eperon, S. D. Stranks, C. Menelaou, M. B. Johnston, L. M. Herz, H. J. Snaith, Energy Environ. Sci. 2014, 7, 982.

[84] N. Pellet, P. Gao, G. Gregori, T. Y. Yang, M. K. Nazeeruddin, J. Maier, M. Grätzel, Angew. Chem. Int. Ed. 2014, 53, 3151.

[85] C. C. Stoumpos, C. D. Malliakas, M. G. Kanatzidis, Inorg. Chem. 2013, 52, 9019.

[86] A. Sadhanala, F. Deschler, T. H. Thomas, S. E. Dutton, K. C. Goedel, F. C. Hanusch, M. L. Lai, U. Steiner, T. Bein, P. Docampo, J. Phys. Chem. Lett. 2014, 5, 2501

[87] F. Hao, C. C. Stoumpos, R. P. Chang, M. G. Kanatzidis, J. Am. Chem. Soc. 2014, 136, 8094.

[88] G. Nedelcu, L. Protesescu, S. Yakunin, M. I. Bodnarchuk, M. J. Grotevent, M. V. Kovalenko, Nano Lett. 2015, 15, 5635.

[89] Q. A. Akkerman, V. D'Innocenzo, S. Accornero, A. Scarpellini, A. Petrozza, M. Prato, L. Manna, J. Am. Chem. Soc. 2015, 137, 10276.

[90] D. Cortecchia, S. Neutzner, A. R. Srimath Kandada, E. Mosconi, D. Meggiolaro, F. De Angelis, C. Soci, A. Petrozza, J. Am. Chem. Soc. 2016, 139, 39.

[91] V. K. Ravi, G. B. Markad, A. Nag, ACS Energy Lett. 2016, 1, 665.

[92] S. Adjokatse, H.-H. Fang, M. A. Loi, Mater. Today 2017, 20, 413.

[93] H. Huang, A. S. Susha, S. V. Kershaw, T. F. Hung, A. L. Rogach, Adv. Sci. 2015, 2, 1500194.

[94] A. K. Guria, S. K. Dutta, S. D. Adhikari, N. Pradhan, ACS Energy Lett. 2017, 2, 1014.

[95] N. Pradhan, S. Das Adhikari, S. K. Dutta, A. Dutta, A. K. Guria, Angew. Chem. Int. Ed. 2017, 56, 8746. 
[96] W. Liu, Q. Lin, H. Li, K. Wu, I. Robel, J. M. Pietryga, V. I. Klimov, J. Am. Chem. Soc. 2016, 138, 14954.

[97] J. Zhu, X. Yang, Y. Zhu, Y. Wang, J. Cai, J. Shen, L. Sun, C. Li, J. Phys. Chem. Lett. 2017, 8, 4167.

[98] H. Huang, M. I. Bodnarchuk, S. V. Kershaw, M. V. Kovalenko, A. L. Rogach, ACS Energy Lett. 2017, 2, 2071.

[99] B. Akbali, G. Topcu, T. Guner, M. Ozcan, M. M. Demir, H. Sahin, Phys. Rev. Mater. 2018, 2, 034601.

[100] C. C. Stoumpos, C. D. Malliakas, J. A. Peters, Z. Liu, M. Sebastian, J. Im, T. C. Chasapis, A. C. Wibowo, D. Y. Chung, A. J. Freeman, Cryst. Growth Des. 2013, 13, 2722.

[101] H. C. Wang, S. Y. Lin, A. C. Tang, B. P. Singh, H. C. Tong, C. Y. Chen, Y. C. Lee, T. L. Tsai, R. S. Liu, Angew. Chem. Int. Ed. 2016, 55, 7924.

[102] S. Bhaumik, S. A. Veldhuis, Y. F. Ng, M. Li, S. K. Muduli, T. C. Sum, B. Damodaran, S. Mhaisalkar, N. Mathews, Chem. Commun. 2016, $52,7118$.

[103] Y. Shirasaki, G. J. Supran, M. G. Bawendi, V. Bulović, Nat. Photon. 2013, 7, 13.

[104] C. C. Lin, A. Meijerink, R.-S. Liu, J. Phys. Chem. Lett. 2016, 7, 495.

[105] J. Zhou, Z. Hu, L. Zhang, Y. Zhu, J. Alloys Compd. 2017, 708, 517.

[106] J. Zhou, F. Huang, H. Lin, Z. Lin, J. Xu, Y. Wang, J. Mater. Chem. C 2016, 4, 7601.

[107] Y. H. Song, S. H. Choi, J. S. Yoo, B. K. Kang, E. K. Ji, H. S. Jung, D. H. Yoon, Chem. Eng. J. 2017, 313, 461.

[108] E. I. Hormats, F. C. Unterleitner, J. Phys. Chem. 1965, 69, 3677.

[109] X. Di, J. Jiang, Z. Hu, L. Zhou, P. Li, S. Liu, W. Xiang, X. Liang, Dyes Pigm. 2017, 146, 361.

[110] C.-W. Sher, C.-H. Lin, H.-Y. Lin, C.-C. Lin, C.-H. Huang, K.-J. Chen, J.-R. Li, K.-Y. Wang, H.-H. Tu, C.-C. Fu, Nanoscale 2016, 8, 1117.

[111] K. Bi, D. Wang, P. Wang, B. Duan, T. Zhang, Y. Wang, H. Zhang, Y. Zhang, J. Nanoparticle Res. 2017, 19, 174.
[112] S. Pathak, N. Sakai, F. Wisnivesky Rocca Rivarola, S. D. Stranks, J. Liu, G. E. Eperon, C. Ducati, K. Wojciechowski, J. T. Griffiths, A. A. Haghighirad, Chem. Mater. 2015, 27, 8066.

[113] M. Meyns, M. Perálvarez, A. Heuer-Jungemann, W. Hertog, M. Ibáñez, R. Nafria, A. Genç, J. Arbiol, M. V. Kovalenko, J. Carreras, ACS Appl. Mater. Interfaces 2016, 8, 19579.

[114] Y. Wei, X. Deng, Z. Xie, X. Cai, S. Liang, P. a. Ma, Z. Hou, Z. Cheng, J. Lin, Adv. Funct. Mater. 2017, 27, 1703535.

[115] E. Jang, S. Jun, H. Jang, J. Lim, B. Kim, Y. Kim, Adv. Mater. 2010, 22, 3076.

[116] H. Wang, H. Lin, X. Piao, P. Tian, M. Fang, A. Xue'e, C. Luo, R. Qi, Y. Chen, H. Peng, J. Mater. Chem. C 2017, 5, 12044.

[117] K. Ma, X.-Y. Du, Y.-W. Zhang, S. Chen, J. Mater. Chem. C 2017, 5, 9398.

[118] T. Otto, M. Müller, P. Mundra, V. Lesnyak, H. V. Demir, N. Gaponik, A. Eychmüller, Nano Lett. 2012, 12, 5348.

[119] M. Adam, Z. Wang, A. Dubavik, G. M. Stachowski, C. Meerbach, Z. Soran-Erdem, C. Rengers, H. V. Demir, N. Gaponik, A. Eychmüller, Adv. Funct. Mater. 2015, 25, 2638.

[120] T. Erdem, Z. Soran-Erdem, Y. Kelestemur, N. Gaponik, H. V. Demir, Opt. Express 2016, 24, A74.

[121] M. Müller, M. Kaiser, G. M. Stachowski, U. Resch-Genger, N. Gaponik, A. Eychmüller, Chem. Mater. 2014, 26, 3231.

[122] W. Xu, Z. Cai, F. Li, J. Dong, Y. Wang, Y. Jiang, X. Chen, Nano Res. 2017, 10, 2692.

[123] Y.-W. Zhang, G. Wu, H. Dang, K. Ma, S. Chen, Ind. Eng. Chem. Res. 2017, 56, 10053.

[124] F. Palazon, F. Di Stasio, Q. A. Akkerman, R. Krahne, M. Prato, L. Manna, Chem. Mater. 2016, 28, 2902.

[125] L. De Trizio, M. Prato, A. Genovese, A. Casu, M. Povia, R. Simonutti, M. J. Alcocer, C. D'Andrea, F. Tassone, L. Manna, Chem. Mater. 2012, 24, 2400.

[126] S. Christodoulou, G. Vaccaro, V. Pinchetti, F. De Donato, J. Grim, A. Casu, A. Genovese, G. Vicidomini, A. Diaspro, S. Brovelli, J. Mater. Chem. C 2014, 2, 3439.

[127] F. Palazon, Q. A. Akkerman, M. Prato, L. Manna, ACS Nano 2015, 10, 1224. 